\title{
Nutrition education in public elementary schools of São Paulo, Brazil: the Reducing Risks of Illness and Death in Adulthood project
}

\author{
Educação nutricional no ensino público fundamental \\ em São Paulo, Brasil: projeto Redução dos Riscos de \\ Adoecer e Morrer na Maturidade
}

Cristina Pereira GAGLIANONE ${ }^{1}$

José Augusto de Aguiar Carrazedo TADDEI'

Fernando Antonio Basile COLUGNATI ${ }^{1}$

Clarissa Góes MAGALHÃES ${ }^{1}$

Giovana Mochi DAVANÇO ${ }^{1}$

Lino de MACEDO²

Fábio Ancona LOPEZ ${ }^{1}$

\section{A B S T R A C T}

\section{Objective}

The objective of this article was to analyze the development, implementation and impact of a nutrition education program on the knowledge and attitudes associated with healthy eating habits.

\section{Methods}

Controlled randomized trial comprising teachers and children of eight public schools; three of them were submitted to educational activities and the remaining ones were kept as controls. Effects of nutrition education were measured in terms of knowledge and attitudes.

\section{Results}

The results revealed an improvement in the food choice among students and a reduction in the intake of foods with high energy density. An improvement in the knowledge and attitudes of the teachers towards the prevention of obesity was also observed.

\footnotetext{
${ }_{1}^{1}$ Disciplina de Nutrologia, Departamento de Pediatria, Universidade Federal de São Paulo. Rua Loefgreen, 1647, 04040-032, São Paulo, SP, Brazil. Correspondência para/Correspondence to: J.A.A.C. TADDEI. E-mails: <taddei.dped@epm.br> ou $<$ nutmet@terra.com.br>.

2 Instituto de Psicologia, Departamento de Psicologia da Aprendizagem, Desenvolvimento e Personalidade, Universidade de São Paulo. São Paulo, SP, Brazil.
} 


\section{Conclusion}

Even with a positive attitude regarding the development of this proposal, there was a lack of support from the studied schools. Future studies and a greater involvement by the Health and Education sectors could overcome such barriers, improving the results of school-based programs to prevent obesity.

Indexing terms: nutrition education; child nutrition; obesity; prevention \& control.

\section{R E S U M O}

\section{Objetivo}

O objetivo deste estudo é analisar o desenvolvimento, implementação e impacto de um programa de educação nutricional sobre conhecimentos e atitudes relativos a hábitos alimentares saudáveis.

\section{Métodos}

Trata-se de estudo randomizado controlado, que envolveu estudantes e professores de oito escolas públicas. Três dessas escolas foram submetidas a uma intervenção educativa, educação nutricional, e as demais foram controle. Avaliaram-se os efeitos da educação nutricional sobre conhecimentos e atitudes.

\section{Resultados}

Observou-se uma melhora na escolha alimentar dos estudantes e redução no consumo de alimentos com alta densidade energética. Também se observou melhora nos conhecimentos e atitudes de professores em relação à prevenção da obesidade.

\section{Conclusão}

Mesmo com uma atitude positiva em relação ao desenvolvimento desta proposta, houve falta de apoio por parte das escolas estudadas. Futuros estudos e um maior envolvimento dos setores de Educação e Saúde poderiam superar essas barreiras, melhorando os resultados de programas nas escolas voltados para a prevenção da obesidade.

Termos de indexação: educação nutricional; nutrição da criança; obesidade; prevenção e controle.

\section{INTRODUCTION}

In the last decades, there have been important advances in children's health conditions throughout the world. A significant decrease in the incidence of infectious diseases has been observed due to a wider adoption of public health and hygiene measures. Regardless, urban life has been associated with undesirable changes in behavior, especially regarding dietary habits and physical activities - factors that are significantly related to obesity'.

In 1989, there were close to 1.5 million obese children in Brazil. The changes that occurred between 1989 and 1996 showed an increased overweight prevalence among infants below two years of age from low socioeconomic classes. A study conducted by the National Institute of Food and Nutrition (Instituto Nacional de Alimentação e Nutrição - PNSN) ${ }^{2}$ in 1989 revealed that $32 \%$ of the Brazilian adult population presents some degree of excess weight and/or obesity. There is a clear association between obesity and cardiovascular diseases; this latter being the foremost cause of death in Brazil. It is estimated that the prevention of overweight/obesity could reduce the incidence of these pathologies by at least 30\%. Recent studies on food consumption by children and adolescents have shown that their diet lacks fruit, vegetables and cereals, but is rich in sugar and fats ${ }^{3}$.

Brazilian dietary patterns have changed over the last three decades with an increased consumption of saturated fats and a $20 \%$ decrease in the consumption of complex carbohydrates. Comparison of a 1988 National Survey with a previous survey (1974-1975) showed that the Brazilian population reduced the consumption of 
basic food items, such as rice and beans, and increased the consumption of soy oil, sugar, eggs, milk, margarine and butter ${ }^{2}$.

Diet and physical activity are key factors for preventing obesity, cardiovascular diseases, cancer and diabetes. Such factors influence health throughout life, even in early periods. The Commission on Macroeconomics and Health stated that strategies to fight these diseases could be effectively addressed by relatively low-cost interventions, especially through preventive activities related to diet, smoking and lifestyle. This is a cost-effective and sustainable means to control such diseases, thereby reducing human suffering and increasing economic productivity and limiting the growing costs of treatment.

The rationale for heath promotion and primary prevention of cardiovascular diseases in youth is based on the high prevalence of the disease among adults, its early insidious onset, the dynamic character of the trends in risk and incidence and the findings that age-related increases in risk factors are, to a large extent, lifestyle related and, as such, can potentially be modified.

Risk factors should be tackled in an integrated manner to ensure that a multidisciplinary and multi sectoral approach is a governing goal of the global strategy. High priority should be given to policies that influence patterns of diet and physical activity. Both research and intersectoral collaboration emphasizing links between health and education should be encouraged ${ }^{1}$.

The Constituição Federal do Brasil of 1988, dealing specifically with 'health as a right to all and a responsibility of the State', recommended implementing economic and social policies aimed at reducing the risks of illness and other health impairments. Universal and equitable access to activities and services for the promotion, protection, and recovery of health within a Sistema Único de Saúde (SUS) is advocated. In 1971, Brazilian Law \# 5692 introduced "Health" themes in the school curriculum, with the objective of encouraging children and adolescents to develop healthy habits. In 1977, the Brazilian Federal Council of Education restated that health should be approached as a 'concern and consequence' of the educational process. Health is a right of all Brazilians and its promotion should be intrinsic to every curriculum objective. However, there is a lack of Nutrition Education (NE) curricula and related audio-visual materials for the promotion of activities aiming at the promotion of healthy eating habits in Brazilian schools.

The school constitutes an appropriate environment for preventive actions, as it represents the most important social grouping after the family. There appears, therefore, to be an opportunity for preventive action among school-aged children, through the promotion of healthy eating habits and more physical activities ${ }^{4}$.

Nutrition Education messages for children are more effective when they are specifically directed towards behavior and supported by school nutrition programs. Although young children can lack the cognitive development to bring behavior into alignment with health beliefs, they are still aware that "nutrition" is somehow important and are building a knowledge basis for future reference when there will be greater interaction between knowledge and self-regulation ${ }^{5}$. The concern over initiating nutritional education among children at an early age is based on the fact that their eating habits acquired in childhood will have a lifelong effect on the individual's eating behavior ${ }^{6}$.

Balanced diets since childhood promote ideal growth, intellectual development and consequently prevent both nutritional deficiencies and obesity ${ }^{7}$. Health habits are rooted in familial practices. Nevertheless, schools have a vital role in promoting the nation's health. Teachers have an important influence towards the students' attitudes encompassed by their expressive contact and involvement in both school and social environments. A study conducted by Doyle \& Feldman ${ }^{8}$ suggests that social insertion acts as a determinant in the efficacy of learning. The closer the social similarity between the people who transmit the message and the target group, the better will be the intervention result. It indicates 
the teacher as a key figure for school health promotion.

Several countries have carried out studies on the implementation of NE programs in schools aimed at augmenting the knowledge regarding nutrition among the children and their parents, thus improving their eating behavior, and hence, their health ${ }^{1,4-8}$. In 2000, an initiative was undertaken to develop and test the efficacy of a multidisciplinary program in Elementary Schools in São Paulo (Brazil) in order to reduce obesity risk factors by promoting healthy lifestyle habits. The project was entitled "Reducing Risks of Illness and Death in Adulthood" (RRIDA) ${ }^{9}$. This project developed and tested educational strategies in health promotion, taking into account the reality of the Brazilian public school environment. It comprised interdisciplinary programs aimed at reducing the risk factors for obesity by stimulating the adoption of healthy eating habits and physical activities.

The objective of the present article was to analyze the development and implementation of the RRIDA Project Nutrition Education component and its impact on knowledge and attitudes regarding healthy eating habits of both students and teachers. The attitudes and practices of teachers towards the implementation of $\mathrm{NE}$ programs at school were also assessed.

\section{METHODS}

The Research Ethics Committee of the Universidade Federal de São Paulo approved the RRIDA Project. The RRIDA staff obtained permission from both directors and parents of the participating schools. Agreements between the project staff and pedagogical coordinators of schools established the best ways to approach the teachers and children, without disturbing the school routine.

The RRIDA project was a Controlled Trial in which both teachers and children, enrolled in three of the eight participating public schools, were submitted to educational activities (intervention group) and the five remaining schools were concomitant controls (control group). Initially, the study planned four schools in the intervention group and four in the control group; however one school refused to participate in the intervention group and, therefore, was later classified as part of the control group. Comparison of anthropometric and social demographic data shows that the children and teachers of the intervention and control groups were similar in the baseline observations.

The present article includes the evaluation process of the educational program by: 1) formative evaluation and 2) assessing data of two trials developed in the context of the RRIDA Project. The first sub trial (sub trial 1) was a study with students and the other (sub trial 2) a study with teachers. Both trials are presented as evaluation studies of nutrition education program outcomes.

Formative evaluation consisted of interviews with 12 teachers immediately after the end of the nutrition education classes for the school children (September, 2000).

In sub trial 1, the baseline assessment of randomly selected students of eight intervention and control groups, enrolled in the $1^{\text {st }}$ and $2^{\text {nd }}$ grades, occurred in 2000. In the next school year (March, 2001) the same children were evaluated again with the same methodology. The results of both intervention and control groups were then compared. Likewise, the teachers' knowledge/ attitude evaluation (sub trial 2) - was also conducted one year after the intervention (September, 2001).

\section{Intervention}

Nutrition Education Program development: the RRIDA's NE program development used as its theoretical framework the Social Cognitive Theory, which addresses both the psychosocial dynamics influencing health behavior and methods of promoting behavioral change ${ }^{10}$. The pedagogical approach for the NE program was based on Piaget's Theory, which provides a useful framework for nutrition educators in supplying appropriate teaching strategies ${ }^{11}$. Connors et al. ${ }^{5}$ reinforces that elementary school children use concrete experiences rather than abstract ones to understand their world. Learning methods also included 
modeling, self-monitoring, problem solving reinforcement and educational games. Thus, concepts of healthy food choices were developed among the children through role-play during regular classes.

The NE program of the RRIDA Project was conceived considering the teacher as one of the key elements in promoting healthy eating habits. For this reason the teachers were trained in terms of how to address their students in the classes regarding the nutrition education issue. A pedagogical approach was adopted based on process homology, in which, during their training, the teachers experienced all activities proposed for the children, notably using games and problemsolving activities ${ }^{12}$.

One of the first steps taken during the intervention planning was the development of adequate materials and techniques, especially developed for students who were not totally literate. They comprised educational games and a story, focused on the relationship between eating and well being.

The goals of these proposed activities were to enhance knowledge, skills and positive attitudes among both children and teachers. The rationale of this educational approach was to broadly understand food and nutrition issues as a means to stimulate healthy food choices, using the food group classification as a model. Teachers should develop activities aimed at not only stimulating adequate food choices but also at reinforcing other important aspects of healthy eating habits (timing of meals, low addition of salt and fat in food, and avoid watching TV during meals).
- Teachers' nutrition education training: teachers of the $1^{\text {st }}$ and $2^{\text {nd }}$ grades of the three intervention schools were invited to participate in a 30-hour training program provided by the training RRIDA project staff comprising three nutritionists, two physical education teachers and one pediatrician. Enrolled teachers attended two sessions per week for six weeks. Each training session lasted $150 \mathrm{~min}$. Eight of the sessions concentrated on nutrition themes and four on physical activity. The focus was on teaching children to choose foods from all the food groups and consume the recommended number of portions from each food group on a daily basis. To do this they should establish a dietary pattern with a regular number and timing of balanced meals while avoiding excessive consumption of fat, sugar and sodium, and increasing ingestion of fiber (Table 1).

After the training, teachers implemented the nutrition education program in their classes, under the supervision of the RRIDA project training staff. Teachers and the RRIDA project training staff met once every three weeks during teaching activities to discuss and solve program difficulties.

- Students' nutrition education activities: the students' NE activities consisted of a curriculum, developed by the RRIDA research staff (one specialist in public health, two in psychopedagogy, one in nutrition and one in physical activity that lasted fourteen weeks). Starting one week after the end of the teachers' training, it included three activities per week. The program contents were developed using the proposed techniques and materials (educational games and stories). Then, the students' activities were implemented using the same contents

Table 1. Contents of Nutrition Education.

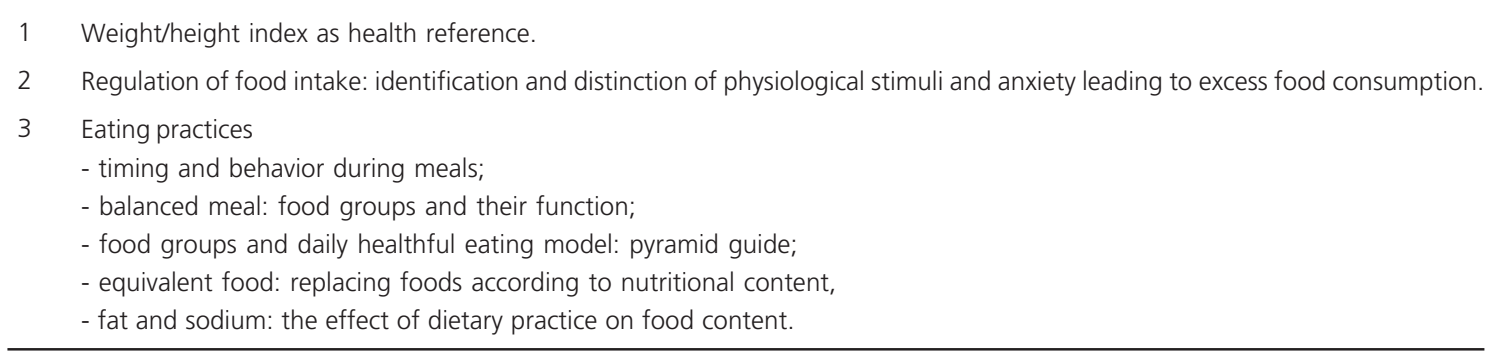


(Table 1) plus the pedagogical approach the teachers experienced during their training (process homology). Each student's activity lasted approximately 30 minutes, eventually reaching the total 22 hours of teaching to complete the full curriculum.

In order to evaluate the effectiveness of the proposed nutrition education curriculum, a formative evaluation took place. The purpose of formative evaluations is to assess program implementation and to detect its strength and weakness ${ }^{13,14}$.

Right from the start of the RRIDA project, the schools showed considerable interest in the education proposal. During the teacher training, their willingness to participate and motivation to implement the education program was evident.

In order to evaluate the launching of the project, immediately after implementing the program of nutrition education for the pupils, 23 classroom teachers (approximately 35 students per class) who had participated in the training were looked up. Of this group, 12 were submitted to an individual and structured interview and a questionnaire composed of open and closed questions, which was applied by the nutritionist responsible for the training and supervision. The classroom activities were assessed according to a qualitative and quantitative approach. The teachers were asked the number of times that each activity was developed and their personal evaluation of the benefits and difficulties in its implementation. They were also encouraged to comment on the NE program and suggest changes in the curriculum and planning that would result in greater effectiveness.

\section{Sub trial 1: students' evaluation ${ }^{15}$}

The sample comprised 803 students randomly selected (7 to 10 -year-old boys and girls) attending the $1^{\text {st }}$ and $2^{\text {nd }}$ grades of eight elementary schools (367 from intervention schools and 436 from control ones). This sample size was defined to detect the differences between intervention and control groups with significance of 0.03 and a power of 0.80 . For this sub trial, considering the partially illiterate condition of most of the students, questions regarding food and behavioral situations were presented as illustrations rather than written text, in accordance to validated instruments used in previous studies ${ }^{15}$. The students answered the questionnaire twice: immediately before beginning the NE and one year after.

The illustrated instrument was evaluated according to: - eating practices during meals: consumption of foods while watching TV or sitting at the table. Students were instructed to circle the picture corresponding to their practice at home, - eating preferences and consumption: children circled the five foods they ate more frequently, and the one they liked best for lunch. The choices were classified as "adequate" when all food groups were included, as presented in the food pyramid model Dietary Guidelines for Americans or as "inadequate" when at least one food group was rejected.

One year after the pre-intervention evaluation and 6 months after the end of the nutrition education activities, the same students of both sample groups (intervention and control) were submitted to another evaluation, using the same procedures adopted in the pre-intervention evaluation. However, there were losses in the study, due to children moving to another school or being excluded after three successive failures to undergo the post intervention evaluation. These reduced the final sample to a total of 637 students (294 in the intervention group and 343 in the control group) Nevertheless, these losses did not compromise the homogeneity of the sample.

\section{Sub trial 2: teachers' evaluation}

A sample that comprised 51 teachers of the $1^{\text {st }}$ and $2^{\text {nd }}$ grades ( 15 in the intervention and 36 in the control group) was selected one year after the end of the teachers'nutrition education 
training program. The objective was to evaluate the impact of this program on the teachers' knowledge/attitudes towards the development of activities for healthy eating promotion during their regular classes. For this purpose, teachers answered a questionnaire with open and multiplechoice questions. Teachers were evaluated regarding their concepts on recommended daily eating, balanced meal and healthy eating patterns using the pyramid guide as a reference ${ }^{16}$. Knowledge was evaluated according to the answers to multiple-choice questions, and attitudes according to the answers to open questions. The answers to the open questions were classified as a positive attitude when the teachers considered themselves as key elements in the development of healthy eating habits among the students and also, when they considered that the school is committed to promote health in its environment.

The chi-square test was used to describe the frequencies and the associations between variables in the schoolchildren of each group at the baseline. The methodology of generalized linear models was used in the pre- and post-intervention comparisons for the percentage of adequate answers to questions. The estimation procedure adopted was the Generalized Estimation Equation (GEE) ${ }^{17}$ using the binomial distribution family for the errors, identity link function and average correlation structure, which resulted in estimates of the effects attributable to the intervention. The Stata 7.0 software ${ }^{18}$ was used for the statistical calculations.

\section{RE S U L T S}

The students' food preferences, attitudes and behaviors according to the questionnaire results were as follows: $81.2 \%$ of students of the intervention group and $81.1 \%$ of those in the control group, respectively, reported having their meals at the table - a behavior considered adequate. This behavior, however, changed very little after the intervention, and no significant differences were observed between groups.

Results showed that the nutrition education program had a positive impact on adequate preference for the grain and pasta food group, according to the choice of at least one item of this food group as most preferred. Even with the score of adequate answer increasing in both groups (intervention from 72.2 to 86.5 and control from 68.3 to 74.3$)$, the intervention group continued to show a significantly higher increase in adequate preference for such foods $(p=0.003)$. A lower preference for foods classified as "risk group" (i.e. those rich in fats and simple/non-complex sugars) was also detected. Before the intervention, $82.2 \%$ of the intervention group and $79.6 \%$ of the control group included foods in this group among their favorites. After the intervention, these percentages fell to $57.9 \%$ and $70.6 \%$, respectively. Thus, the response pattern to the variable "preference for foods in the risk group" of both intervention and control groups $(p<0.001$ and $p=0.007$, respectively) improved after the intervention. Moreover, following the intervention, the effect of time $x$ exposure interaction showed that there was a higher increase of adequate answers among the intervention group than among the controls $(p=0.012)$

Regarding the teachers' knowledge and attitudes, a significant increase in knowledge related to recommended daily food intake (46.7\% intervention and $5.6 \%$ control, $p<0.001)$ and balanced meal (86.6\% intervention and $27.8 \%$ control, $p<0.001)$ were observed in the intervention group. An increase was also observed in positive attitudes towards the development of NE programs in schools $(100.0 \%$ intervention and $69.4 \%$ control, $p=0.021$ ). Teachers from the intervention schools tended to take personal responsibility for developing health promotion actions among students.

The implementation of nutrition education program at school and the results of the evaluation process pointed to many unexpected barriers: - even though all enrolled teachers 
showed positive attitudes to developing the NE program, most mentioned difficulties in implementing the program, because of the school calendar and other educational priorities (the need to spend more time with traditional subjects, such as mathematics and languages); - half of the invited teachers from the three intervention schools attended the training course, but then failed to implement the proposed activities with their students. Difficulties in teacher attendance were reportedly to be a lack of time to participate in meetings held in the evening after a full working day; - other explanations included lack of motivation faced with other priorities: - teachers did not implement all activities proposed in the nutrition education curriculum, spending only approximately 10 hours (instead of 22) teaching nutrition and even changed the proposed curriculum, by creating new activities; - one of the games, which developed essential concepts about healthy eating, was used by only half of the teachers; - although unexpected barriers occurred to its development, all of the teachers considered the proposed RRIDA's Nutrition Education Program to be relevant.

According to their opinion, the following actions would improve its effectiveness: a) stimulate the involvement of parents in nutrition education activities; b) develop new materials to teach nutrition education, since there is a lack of available resources to teach nutrition in Brazilian Schools; c) adjust the proposed nutrition education curriculum to the regular school teaching plan.

\section{I SCUSSIO N}

While health interventions can take place at many levels, there are two basic targets: factors within the control of individuals or factors beyond the control of individuals. Actions on an individual level target knowledge, attitudes, skills, and beliefs while structural interventions aim to effect changes in the social and physical environment ${ }^{19}$. Nutrition Education at schools exerts an influence on both individual and structural levels since it targets personal and social school patterns.
Process evaluation is an important component for evaluating the impact of health promotion at school, helping to explain some of the weaker aspects of program performance. It assesses the fidelity of implementation, coverage and use of intervention materials, teacher training and curriculum delivery; and was used as a strategy for a more comprehensive approach to program evaluation of school-based programs 20,21. $^{2}$.

Even though health habits are deeply rooted in family habits, schools have a vital role to play in promoting health ${ }^{18}$. Schools provide a suitable setting for health promotion and early intervention; however health promotion is often regarded as tangential to the central mission focused on the teaching of traditional disciplines. On the other hand, negative characteristics of the school organization (school environment itself and low job satisfaction) could have a moderating effect on the results of school-based programs ${ }^{10}$.

Adults contribute to eating behavior by providing information, support, role models and establishing a supportive social context. Shared experiences create social norms and provide opportunities for observing peer behavior ${ }^{5}$. Motivated and instructed teachers should become supportive and stimulators of desirable behavior among students ${ }^{10,22}$.

The Healthy People 2000, published by US Department of Health and Human Services, Public Health Service ${ }^{23}$ stated as a national health objective that by the year 2000, at least 75 percent of schools should provide NE from pre-school through $12^{\text {th }}$ grade. However, according to the "Nutrition Education in US Public Schools: Teacher Survey, K-5", (1997) few teachers (27\%) reported availability of high quality in-service training for NE. It is suggested that at least 50 hours of teaching at elementary school level is needed for an impact on behavior. However, the average number of hours taught at North American schools was 13.

The goal of RRIDA Nutrition Education Program was to stimulate healthful eating patterns among students by developing positive attitudes, skills and knowledge, in addition to improving the 
teachers' awareness and skills, together with providing adequate educational materials for the development of the proposed activities. According to teachers who participated in the RRIDA NE program, other school priorities presented an important barrier to its implementation. Although teachers showed positive attitudes, they mentioned that they faced difficulties in developing all the nutrition education activities proposed due to a lack of time and support from the pedagogical coordination; together with problems in the management of large groups of students (approximately 35 per class) when using new materials and developing new activities.

The curriculum design is based on contemporary educational and behavioral research as well as theoretical models regarding how children learn and how the learning influences behavior. It uses a conceptual and methodological approach adjusted to the development phase, appropriate health instruction as well as the promotion of cognitive and behavioral skills building. A primary goal of the curriculum is to provide the schoolchildren with the knowledge, attitudes and experiences necessary for the practice of healthy behavior. The behavioral goals and learning objectives of the full curriculum are to teach the children to distinguish between healthy and unhealthy food habits and to adopt the former.

Regarding learning aspects, Greidanus \& Contento ${ }^{11}$ mention that cognitive development or cognitive maturity is a major influence on what children are able to learn. In the early school years, children begin to develop the ability to classify and think causally, but their reasoning ability is limited to concrete objects and specific experiences. According to the Piagetian constructivist framework, a learner actively constructs and reconstructs knowledge by a modification of his/her mental process as he/she physically matures, experiences interaction with objects and events and develops and interacts socially ${ }^{11}$. A study comparing the impact of traditional teaching and a pedagogical approach based on games to teach nutritional concepts and to improve food habits demonstrated the best results. In terms of both knowledge and dietary intake, the best results were achieved using games $^{24}$.

The high/scope theory of active learning suggests that children's mental, emotional, social and physical growth is best promoted by creative interactions with people, materials, and ideas through direct and immediate experiences. The RRIDA curriculum promotes both direct and immediate experiences with food choice through activities, such as playing educational games, which offer the children the opportunity to interact with real objects and people.

Nutrition knowledge is a scientific construction that nutrition educators have created to represent an individual's cognitive process related to information about food and nutrition. One assumption underlying nutrition information/ persuasion efforts is that increasing an individual's knowledge (or changing their beliefs) about food and nutrition will bring about desired attitudes and behavior. Given the complexity of food and nutrition issues, NE needs to teach people not only the knowledge that will help to choose foods, but also the analytical and evaluative skills necessary to think broadly about foods and nutrition in an ecologically sensitive and globally interdependent world.

The research on knowledge structure on nutrition and examining how people group objects into their classes (or categories or concepts) provides insight into the meaning associated with these classes, where a class is also defined as a "group". Nutrition educators have considered one type of classification system, namely food guides, as an indispensable tool for offering the public the information needed to obtain appropriate quantities of nutrients. The classification system together with its recommendations, adopted by food guides, transmits both cognitive and behavioral or action concepts. As in our study, the Head Start program targeted illiterate children and used a questionnaire comprised of a multiple-choice picture-quiz for the assessment of the 
program's impact on children's knowledge and understanding regarding health, nutrition and safety issues ${ }^{25}$. Health beliefs and concepts develop early in life, thus justifying that health education should begin at a correspondingly early age.

Eating preferences and health beliefs draw on perceptions of the situational and cognitive evaluation of past experiences. Although young children may lack the cognitive development to bring behavior into alignment with health beliefs they are still aware that "nutrition" is somehow important and as such are building a knowledge base for future reference when there will be greater interaction between knowledge and self-regulation ${ }^{5}$. Some authors believe that children are not reliable sources of information on their own eating preferences. However, a study on the dimensions of eating preferences of pre-school children revealed that three-year-old children do not hesitate to express their preferences and aversions, especially in relation to food ${ }^{26}$.

Regarding preference for foods of the grain and pasta group and the risk group, students of intervention schools presented a significant improvement as a result of the NE program. Grains represent the best caloric source and constitute the basis of a healthy diet, since they provide complex carbohydrates and unsaturated fat. Another aspect of food preferences, the risk group, also pointed to a reduction in preference for fats, oils and sweets, which could translate into a trend towards a healthier food choice. Perhaps these changes in the preferences arose due to the fact that the children were now able to recognize the factors involved in healthy eating habits. This rational is in accordance with the results of another study which showed that the children who had better knowledge on nutrition presented the most positive attitudes, eating practices, made better food choices and had better eating habits ${ }^{27}$.

In spite of the high percentage of children who have their meals at the table, 35\% reported having meals in front of the television. A study carried out in the United States on the impact of television commercials on the food preferences of pre-school children showed that $30 \%$ of the parents reported their children "always or nearly always" ate or drank something while watching television ${ }^{28}$. An appropriate, calm and quiet atmosphere is recommended for children at meals, to ensure these take place adequately.

Significant improvement of the knowledge on nutrition and health of children exposed to intervention programs was also observed in other studies. The higher average level of nutritional knowledge among students exposed to an education program is a result of the adoption of a nutrition curriculum in class, which produces favorable effects of this kind of activity on the cognitive performance of the students ${ }^{29}$. Kristal et al. ${ }^{30}$ suggests that an individual's belief in the importance and benefits of a healthy diet appears to be a strong component of food choice.

Similarly to that reported in other studies on nutrition education, the estimated beneficial effects are of low intensity. "The Child and Adolescent Trial for Cardiovascular Health (CATCH)" has been one of the nutritional programs that achieved important but minor behavioral changes related to disease risk factors ${ }^{31}$.

Nutritional interventions carried out in schools suggest that children do in fact improve their knowledge. Nevertheless, few programs have been successful in actually changing their eating habits. Evaluating the effectiveness of 220 nutrition education programs conducted between 1980 and 1995 concluded that most intervention effects were modest, as observed in the RRIDA Program ${ }^{29}$. This may occur due to our limited comprehension of the child's eating behavior, relatively ineffective intervention strategies, study designs that are not very reliable and to moderating effects of the schools' organizational structure on program outcome. On the other hand, the methods used to measure results might fail to detect behavioral changes. Consequently, knowledge and abilities acquired at school do not necessarily lead to major behavioral changes, at least not in the short run. 


\section{CONCLUSION}

Despite the well-established advantages of encouraging healthy eating habits during infancy as well as the important role of Brazilian schools in promoting quality of life, the development of these school-based programs is faced with barriers at an individual and structural level. According to the results of the RRIDA program, which represents a pioneer experience in the prevention of obesity in Brazilian elementary schools, the development of NE programs faces unexpected barriers: such as lack of teachers' involvement; other school priorities; and various environmental aspects (social and physical). However, the findings of this study suggest that efforts towards nutrition education might have a small but positive impact on the knowledge base and students' preferences, as well as positive changes in both knowledge and attitude of teachers regarding development of NE curricula at schools.

We consider that greater positive effects could be brought about by additional efforts into understanding the beliefs and attitudes of teachers regarding their role in health promotion. Positive attributes should be reinforced, such as adapting the content and pedagogical approach of nutrition education to the regular curriculum. Future studies are needed to better understand how to improve the efficacy and effectiveness of such school-based programs to prevent obesity and decrease risks of disease.

\section{ACKNOWLEDGEMENTS}

The authors extend their thanks to Fundação de Amparo à Pesquisa do Estado de São Paulo (FAPESP), for the financial support (99/07582-6) and to the Secretaria de Educação de São Paulo for collaborating to the development of the RRIDA Project.

\section{REFERENCES}

1. World Health Organization. Resolution WHA53.23. Diet, physical activity and health. In: Fifty-fifth World Health Assembly. Geneva; 2002. v.1.
2. Coitinho D, Leão M, Recine E, Sichieri R. Condições nutricionais da população brasileira: adultos e idosos. Pesquisa Nacional de Saúde e Nutrição (PNSN). Brasília: Instituto Nacional de Alimentação e Nutrição; 1991. 39p.

3. Brasil. Ministério da Saúde. Plano nacional para a promoção da alimentação adequada e do peso saudável. Brasília; 1999.

4. Borra ST, Schwartz NE, Spain CG, Natchipolsky MM. Food, physical activity, and fun: inspiring America's kids to more healthful lifestyles. J Am Diet Assoc. 1995; 95(7):816-23.

5. Connors P, Bednar C, Klammer S. Cafeteria factors that influence milk-drinking behaviors of elementary school children: grounded theory approach. J Nutr Educ. 2001; 33(1):31-6.

6. Baranowski T, Mendlein J, Resnicow K, Frank E, Cullen K, Baranowski J. Physical activity and nutrition in children and youth: an overview of obesity prevention. Prev Med. 2000; 31(2):1-10.

7. The Centers for Disease Control and prevention. Guidelines for school health programs to promote lifelong healthy eating. J Sch Health. 1997; 67(1):9-26.

8. Doyle El, Feldman RH. Factors affecting nutrition behavior among middle-class adolescents in urban area of Northern region of Brazil. Rev Saúde Pública. 1997; 31(4):342-50.

9. Taddei JA, Lopez FA, Macedo L, Gaglianone CP, Bracco MM, Magalhães CG, et al. Risk reduction of illness and deaths in adulthood. the RRIDA project. Brazilian Pediatric News [Internet]. 2000 June [cited 2002 Sept 16]; 2(2): [about 2p]. Available from: http://www.brazilpednews.org.br/ junh2000/pr0002.html

10. Baranowski T, Perry CL, Parcel GS. How individuals, environments, and health behavior interact: social cognitive theory. In: Glanz K, Lewis M, Rimer BK, editores. Health behavior and health education: theory, research, and practice. 2nd ed. San Francisco: Jossey-Bass Publishers; 1997. p.153-78.

11. Greidanus I, Contento I. The relationship between the ability to solve practical nutrition problems in an adult population and Piagetian cognitive levels. J Nutr Educ. 1989; 21(2):73-81.

12. Macedo L, Petty AL, Passos NC. Aprender com jogos e situações problema. Porto Alegre: Artmed; 2000.

13. Patton $M Q$. Qualitative evaluation and research methods. 2nd ed. Newbury Park (CA): Sage; 1980.

14. Dillman DA. Mail and internet surveys: the tailored design method. New York: John Willey \& Sons; 2000 . 
15. Magalhães CG. Impacto de programa educativo nos conhecimentos, preferências e hábitos alimentares de escolares: ensaio randomizado controlado [dissertação]. São Paulo: Universidade Federal de São Paulo; 2002.

16. United States Department of Agriculture and United States Department of Health and Human Services [Internet]. Dietary guidelines for Americans. [cited 2003 Feb 20]. Available from: www.usda.gov/cnpp/dietgdln.pdf

17. Zeger SL, Liang KY. Longitudinal data analysis for discrete and continuous outcomes. Biometrics. 1986; 42(1):121-30.

18. Stata Statistical Software [computer program]. Release 7.0. College Station(TX): Stata Corporation; 2001.

19. Cohen DA, Scribner RA, Farley TA. A structural model of health behavior: a pragmatic approach to explain and influence health behaviors at the population level. Prev Med. 2000; 30(2):146-54.

20. Baranowski T, Stables $G$. Process evaluation of the 5-a-day projects: helping explain outcomes. Health Educ Behav. 2000; 27(2):157-66.

21. Reynolds KD, Franklin FA, Leviton LC, Maloy J, Harrington KF, Yaroch $A L$, et al. Methods, results, and lessons learned from process evaluation of the High 5 school based nutrition intervention. Health Educ Behav. 2000; 27(2):177-86.

22. Davanço GM, Taddei JAAC, Gaglianone CP. Knowledge, attitudes and practices of teachers of basic cycle, exposed and non exposed to a Nutrition Education Course. Rev Nutr. 2004; 17(2):177-84.

23. NCES Fast Responses Survey System [Internet]. Nutrition education in US public schools: elementary teacher survey K-5 FRSS 60. 1997. [cited 2003 Feb 20]. Available from: http://nces.cd.gov/ surveys/frss/publications/20000040/

24. Turnin MC, Tauber MT, Couvaras O, Jouret B, Bolzonella $C$, Bourgeois $\mathrm{O}$, et al. Evaluation of microcomputer nutritional teaching games in 1,876 children at school. Diabetes Metab. 2001; 27(4 Pt 1):459-64.

25. Williams CL, Squillace MM, Bollella MC, Brotanek J, Campanaro L, D'Agostino C, et al. Healthy Start: a comprehensive health education program for preschool children. Prev Med. 1998; 27(2): 216-23.

26. Birch LL. Dimensions of preschool children's food preferences. J Nutr Educ. 1979; 11(2):77-80.

27. Foley CS, Vaden AG, Newell GK, Dayton AD. Establishing the need for nutrition education: III. Elementary students' nutrition knowledge, attitudes, and practices. J Am Diet Assoc. 1983; 83(5):564-8

28. Borzekowski DL, Robinson TN. The 30-second effect: an experiment revealing the impact of television commercials on food preferences of preschoolers. J Am Diet Assoc. 2001; 101(1): 42-6.

29. Contento I, Balch GI, Bronner YL, Lytle LA, Maloney SK, Olsen CME, et al. The effectiveness of nutrition education and implications for nutrition policy, programs and research: a review of research. J Nutr Educ. 1995; 27(Special Issue):279-418.

30. Kristal AR, Patterson RE, Glanz K, Heimendinger J, Hebert JR, Feng Z, et al. Psychosocial correlates of healthful diets: baseline results from the Working Well Study. Prev Med. 1995; 24(3):221-8.

31. Sallis JF, Chen AH, Castro CM. School-based interventions for childhood obesity. In: Cheung LW, Richmond JB, editors. Child health, nutrition and physical activity. Champaign (IL): Human Kinetics; 1995. p.179-203.

Submitted on: 14/6/2005

Final version resubmitted on: 12/8/2005 Approved on: 24/8/2005 